\title{
ANÁLISE DE CRESCIMENTO DE MUDAS DE JACAREÚBA (Calophyllum angulare A. C. SMITH - GUTTIFERAE) CULTIVADAS EM CONDIÇÕES DE VIVEIRO.
}

\author{
Kikue MUROYA', Vania Palmeira VARELA ${ }^{2}$, Moacir A. A. CAMPOS ${ }^{2}$
}

RESUMO - O presente trabalho, conduzido no viveiro da Reserva Florestal Adolfo Ducke, Amazonas, Brasil, teve como objetivo comparar quatro niveis de sombreamento no crescimento de mudas de jacareúba (Calophyllum angulare), Foram utilizados os niveis de sombreamento 30,50 e $70 \%$, obtidos com telas de poliolefinas de cor preta, e o nível $0 \%$ a pleno sol. A análise de crescimento foi feita imediatamente após a transferência das mudas para os canteiros e mensalmente durante 5 meses. Foram obtidos os seguintes resultados: a) Os maiores valores de altura; diâmetro do coloe área foliar foram obtidos nas mudas cultivadas sob $70 \%$ de sombreamento aos 150 dias de permanência no viveiro; b)Ocorreu uma tendência de decréscimo nos valores de taxa de crescimento relativo foliar e de razão de área foliar em decorrência do período de permanência das mudas no viveiro, c) A taxa de crescimento relativo foliar não foi influenciada pelos niveis de sombreamento; d) As mudas cultivadas sob $70 \%$ apresentaram valores de taxa de crescimento relativo da parte aérea que indicam uma melhor adaptação a essa condição; com relação a taxa de crescimento relativo das raizes, os níveis de sombreamento mais favoráveis foram 0 e $50 \%$; e) O efeito da aclimatação sobre as mudas cultivadas sob $70 \%$, provocou uma diminuição temporária nas taxas de crescimento relativo da parte aérea e crescimento relativo total, entre os periodos de 30 a 60 dias.

Palavras chaves: crescimento, sombreamento, Calophyllum angulare.

Growth Analysis of Jacareúba (Calophyllum angulare A.C. Smith - Guttiferae) Seedlings Cultivated in Nursery Conditions.

ABSTRACT - This work conducted at the nursery of Ducke Forest Reserve in Amazonas State, Brazil, had as objective to compare four levels of shading on the growth of jacareúba (Calophyllum angulare) seedlings. The following shading levels were used: 30,50 and $70 \%$ by using black plastic screening and $0 \%$ under full sunlight. The growth analysis was done just after the transportation of transportation of seedlings to the beds and monthly during five months. The following results were obtained: a) The greatest values in height, collar diameter and leaf area were obtained with the seedlins cultivated at $70 \%$ of shading-shading at 150 days of staying in the nursery; $b$ ) There was a trend to decreasing the relative foliar growth rate and that of foliar area rate of the seedlings while staying in the nursery; c) The relative foliar growth rate was not influenced by the different levels of shading; d) The seedlings cultivated under $70 \%$ of shading showed values of a relative shoot growth rate wich shows better adaptation to this condition; concerning to therelative root growth rate the levels of shading more favorables were $0 \%$ and $50 \%$; e) The effect of acclimatization on seedlins cultivated under $70 \%$, caused a temporary decrease to the relative growth rate of shoot and the total growth rate between 30 and 60 days.

Key words: growth, shading, Calophyllum angulare

\section{INTRODUÇÃO}

\section{A exploração da floresta amazônica} de forma desordenada e seletiva, em face da demanda por espécies de alto valor comercial, sem o devido conhecimento de suas características silviculturais, pode resultar na perda de recursos florestais bastante valiosos.

Diante da devastação das matas naturais, o conhecimento das técnicas de produção de mudas constitui-se numa alternativa viável para recomposição

Estudante de Engenharia Florestal do Instituto de Tecnologia da Amazônia (UTAM), CEP 69050.020, Manaus-Am.

2 Instituto Nac. de Pesq. da Amazônia (INPA, Cx. Postal 478, CEP 69.083.000, Manaus-Am. 
efetiva das matas exploradas como forma de garantir, através dos sistemas de regeneração artificial, a continuidade deste potencial econômico. Por outro lado, no que se refere à regeneração artificial de espécies florestais, tem-se cada vez mais a demanda por projetos de reflorestamento com espécies nativas para cumprir a obrigação legal de reposição e para obtenção de madeira de qualidades diferenciadas.

Dentre as espécies que vêm sendo exploradas na Amazônia destacam-se as jacareúbas (Calophyllum angulare A.C. Smith) cuja madeira tem sido utilizada pelas serrarias localizadas na região. Uma das jacareúbas, a de maior importancia econômica, pertencente à família Guttiferae, ocorre com maior freqüência em mata de terra firme, e é encontrada também nas margens de rios e igarapés em solos mais arenosos.

Informações sobre a fenologia da jacareúba são mostradas nos estudos feitos por ALENCAR et al. (1979). A floração e a frutificação ocorreram no intervalo de dois anos de 1965 a 1971 e a partir de 1976 apresentaram irregularidade. $O$ periodo de floração foi de abril a agosto e o da frutificação de junho a dezembro.

As espécies são classificadas em grupos ecológicos distintos, de acordo com sua capacidade de adaptação às condições de baixa ou alta intensidade luminosa. Comumente, classifica-se as espécies em plantas de sol e de sombra com base em certas variáveis de resposta à intensidade luminosa.

BLACKMAN \& WILSON (1956) definiram como planta de sol aquela que apresenta uma alta razão entre área foliar e unidade de peso seco total na unidade de tempo (Razão de área foliar - RAF) a pleno sol. Ocorre mudança neste índice à intensidades de luz mais baixas. Ao contrário, as plantas de sombra apresentam uma baixa RAF a pleno sol e um rápido aumento deste índice com o aumento do sombreamento.

BLACKMAN (1968) adotou como critério a taxa de crescimento relativo (acúmulo de matéria seca na unidade de tempo - TCR): as plantas de sol apresentam TCR maior a uma intensidade relativa de luz de $100 \%$ (pleno sol) enquanto as de sombra apresentam uma TCR máxima abaixo de $100 \%$ de iluminação.

Existem espécies que evitam o déficit de luz, ou seja, apresentam mecanismo de aumentar a quantidade de luz disponivel pela fotossintese (LEVITT, 1972); espécies que toleram a sombra capazes de ajustar suas taxas metabólicas para sobreviverem a baixas intensidades de luz (GRIME, 1965) e espécies intolerantes, que sobrevivem à sombra (CLARKE, 1971).

Vários autores têm utilizado o método do sombreamento artificial para avaliar o comportamento das mudas de espécies florestais quanto à intensidade luminosa. Há, porém, poucos resultados de pesquisas sobre qualidade de mudas de espécies florestais de regiões tropicais.

O comportamento das mudas de espécies florestais em relação à luz pode ser avaliado por meio de vários parâmetros. Destacando-se, entre eles, a altura, que é utilizada com freqüência devido à facilidade de avaliação.

FAIRBAIRN \& NEUSTEIN (1970), para as mudas de Pseudotsuga menzienssi, Tsuga heterophylla, Abies 
grandes e Picea abies produzidas com pouco sombreamento, encontraram melhor desenvolvimento em altura, enquanto que observaram maior altura para as mudas de Picea sitchensis sem sombreamento.

Em um estudo de produção de mudas de espécies nativas, FERREIRA et al.(1977), utilizando 4 níveis de sombreamento, concluíram que o tratamento a céu aberto proporcionou maior produção de matéria seca total em mudas de Peltophorum dubium e Hymeneae stigonocarpa, maior diâmetro do colo em mudas de Schizolobium parahyba e H. stigonocarpa e maior razão do comprimento radicular/parte aérea em mudas $P$. dubium e Enterolobium contortisiliquum. Somente a área foliar e a razão de área foliar em mudas de $S$, parahyba foram maiores, com $70 \%$ de sombreamento.

Na produção de mudas Ocotea porosa, STURION \& IEDE (1982), compararam três níveis de sombreamento $(0 \%, 30 \%$ e $60 \%)$ e concluiram que as mudas com maior diâmetro de colo, peso da matéria seca e maiores relações entre o peso de matéria seca do sistema radicular e peso da matéria seca da parte aérea, e entre diâmetro do colo e altura da parte aérea, foram obtidas quando cultivadas a céu aberto. Constataram, porém, menor porcentagem de sobrevivência neste tratamento.

As plântulas de Piptadenia rigida (angico branco), Schizolobium parahyba (guapuruvu) e Albizzia lebbeck (coração de negro) foram cultivadas em casa de vegetação, sob condições de luz total e $80 \%$ de sombra. As três espécies apresentaram um maior crescimento em altura nas condições de sombreamento do que à plena luz. Todavia, apenas as plântulas de $P$. rigida evidenciaram incrementos significativos do peso seco das folhas e da área foliar quando expostas a $80 \%$ de sombra (POGGIANI et al.,1992),

PINTO et al. (1993) compararam quatro diferentes níveis de sombreamento $(0 \%, 30 \%, 50 \%$ e $70 \%)$ em mudas de Licaria canella e concluiram que as mudas produzidas sob $50 \%$ de sombreamento apresentaram maiores valores de peso da matéria seca da parte aérea e do sistema radicular. Observaram, ainda, que a altura, área foliar e razão de área foliar não foram influenciadas significativamente pelos niveis de sombreamento.

Em um estudo sobre produção de mudas de morototó (Schefflera morototoni), cultivadas sob quatro níveis de radiação solar, BARBOSA (1985) concluiu que o sombreamento antecipou e aumentou as taxas de crescimento da espécie, indicando uma facilidade de adaptação em condições ambientais de menor incidência da radiação solar. Observou que ao nível de $50 \%$, a razão de área foliar apresentou pequena variação porém continuamente decrescente e que área foliar específica apresentou valores mais elevados à medida que a radiação solar foireduzida.

O presente trabalho tem como objetivo avaliar a influência do sombreamento nos parâmetros morfológicos e físiológicos de crescimento das mudas de jacareúba, (Calophyllum angulare A. C. Smith), a fim de definir um padrão de qualidade de mudas a serem levadas ao campo. 


\section{MATERIAL E MÉTODOS}

\section{Área de estudo}

\section{Localização}

O experimento foi desenvolvido no viveiro da Reserva Florestal Adolfo Ducke, localizado no km 26 da Rodovia AM-10, Manaus - Itacoatiara. A reserva está compreendida entre as coordenadas geográficas de $03^{\circ} 00^{\prime} 02^{\prime \prime}$ e $03^{\circ} 08^{\prime} 00^{\prime \prime}$ de latitude sul e $59^{\circ} 52^{\prime} 40^{\prime \prime}$ e $59^{\circ} 58^{\prime} 00^{\prime \prime}$ de longitude oeste.

\section{Clima}

O clima da área é do tipo Afi, de acordo com a classificação climatológica de Köppen. Com base em dados meteorológicos de nove anos da Reserva Ducke, (RIBEIRO,1976) constatou que a temperatura média para o mês mais frio nunca é inferior a $18^{\circ} \mathrm{C}$, a precipitação média anual é de $2000 \mathrm{~mm}$ e ocorrem duas estações distintas: a chuvosa, estendendo-se de novembro a maio e a seca, de junho a outubro.

\section{Instalação do experimento}

As sementes foram coletadas no mesmo local da experimentação em 21 de fevereiro de 1994, em árvore com altura total de $29,5 \mathrm{~m}$ e DAP (diâmetro à altura do peito) de $14,5 \mathrm{~cm}$. A semeadura foi realizada, sob galpão coberto com telhas transparentes, no mesmo dia da coleta, utilizando-se sementeira de $100 \times 47 \times 21 \mathrm{~cm}$ e, como substrato, areia lavada. Na repicagem, realizada após 50 dias da semeadura, foram utilizados sacos de polietileno de $16,5 \times 28,5 \mathrm{~cm}$ enchidos com uma mistura de areia e barro na proporção de
$2: 1$. Após 15 dias, as mudas foram distribuidas nos canteiros.

Foram utilizados quatro níveis de sombreamento: $\mathrm{S}_{1}=30 \%, \mathrm{~S}_{2}=50 \%$ e $\mathrm{S}_{3}=70 \%$ obtidos com o uso de telas de poliolefinas, de cor preta, e $\mathrm{S}_{4}=0 \%$ a pleno sol. Em cada parcela, 200 mudas foram distribuídas ao acaso, a espaços de $20 \mathrm{~cm}$, par evitar a sobreposição das folhas entre as mudas. No decorrer da experimentação, os canteiros foram irrigados diariamente e as ervas daninhas, eliminadas.

As avaliações do crescimento das mudas foram feitas imediatamente após a transferência das mudas para os canteiros e mensalmente durante 5 meses, tomandose aleatoriamente amostras de 8 plantas em cada tratamento.

Foram avaliadas as seguintes caracteristicas:

altura total $(\mathrm{cm})$ - medida com o auxílio de uma régua milimetrada até a inserção da última folha.

diâmetro do colo (mm) - com auxílio de um paquímetro.

área foliar $\left(\mathrm{cm}^{2}\right)$ - avaliada através do medidor de área foliar portátil LI-COR Mod LI 3000A.

peso da matéria seca $(\mathrm{g})$ da parte aérea, do sistema radicular e total - as mudas foram seccionadas em duas partes (aérea e radicular)à altura e do colo foram colocadas para secar em estufa a $75^{\circ} \mathrm{C}$ por 48 horas, até atingirem o peso constante, e posteriormente pesadas em balança analítica com precisão de $0,001 g$.

peso da matéria seca da folha $(\mathrm{g})$ as folhas foram separadas e pesadas em balança analítica com precisão de $0,001 \mathrm{~g}$.

Através destas variáveis, foram calculados alguns parâmetros morfo- 
lógicos e fisiológicos e morfológicos de crescimento. Estes parâmentros foram: taxa de crescimento relativo total (TCRT), taxa de crescimento foliar relativo foliar (TCRFFR), taxa de crescimento relativo da parte aérea (TCRPA), taxa de crescimento relativo da raiz (TCRRA) e razão da área foliar (RAF), segundo fórmulas de crescimento de RADFORD (1967).

Os dados de altura, diâmetro do colo e área foliar foram analisados pelo delineamento de blocos do acaso em esquema fatorial $4 \times 5$.

Os dados de taxa de crescimento foliar relativo foliar (TCRF) e razão de área foliar (RAF) foram analisados segundo o delineamento inteiramente ao acaso em esquema de parcelas subdivididas no periodo, sendo que os niveis de sombreamento constituiram as parcelas e os períodos as subparcelas.

Os dados de taxa de crescimento relativo foliar (TCRF) e razão de área foliar (RAF)foram analisados segundo o delineamento inteiramente ao acaso em esquema de parcelas subdivididas no periodo, sendo que os níveis de sombreamento constituiram as parcelas e os periodos, as subparcelas.

\section{RESULTADOS E DISCUSSÃO}

Na Tabela 1, encontram-se as médias de altura das mudas de jacareúba obtidas de acordo com os periodos de avaliação e niveis de sombreamento testados. Observou-se que as mudas avaliadas com 90,120 e 150 dias apresentaram resultados de altura significativamente semelhantes entre si e estatisticamente superiores aos períodos de 30 e 60 dias. Os níveis de sombreamento $0 \%, 30 \%$ e $50 \%$ não apresentaram diferenças significativas na altura das mudas e o nivel de $70 \%$ foi significativamente superior quando comparado com os demais niveis. BARBOSA (1985) também verificou que as mudas de morototó (Schefflera morototoni) apresentaram altura maior em ambientes mais sombreados, em conseqüência da dominância apical. Entretanto, em estudos sobre niveis de sombreamento na produção de angelim pedra (Dinizia excelsa), VARELA \& SANTOS (1992) observaram que o sombreamento de $70 \%$ prejudicou o crescimento em altura das mudas quando comparado com $30 \%$.

A altura possui diferentes padrões de respostas de acordo com a capacidade adaptativa da espécie às variações na intensidade de luz. Para a espécie em estudo, $70 \%$ de sombreamento favoreceu o crescimento em altura das mudas quando comparadas com os demais niveis de sombreamento.

As maiores alturas das mudas sombreadas foram alcançadas, provavelmente, pela dominância apical. A dominância apical aumenta quando as plantas são submetidas a baixo nivel de luminosidade, (PHILLIPS, 1969), em razão do decréscimo de fotoassimilados e maior nivel de auxina (PHILLIPS, 1975).

No que se refere ao sombreamento de $0 \%$, verificou-se através da Tabela 1 , que não ocorreram diferenças estatísticas na altura das mudas entre os períodos de $60,90,120$ e 150 dias e esses resultados foram significamente superiores ao obtido com 30 dias. Para o sombreamento de $30 \%$, os períodos 
Tabela 1. Médias de altura $(\mathrm{cm})$ das mudas de jacareúba obtidas de acordo com os períodos de avaliação e niveis de sombreamento testados.

\begin{tabular}{|c|c|c|c|c|c|c|}
\hline \multirow{2}{*}{ Somb. $(\%)$} & \multicolumn{6}{|c|}{ PERÍODOS (dias) } \\
\hline & 30 & 60 & 90 & 120 & 150 & Médias \\
\hline 0 & B 29,88 & A 38,44 & A 42,25 & $A 43,63 b$ & A $43,50 b$ & $39,54 b$ \\
\hline 30 & C 29,81 & BC 34,44 & A 45,63 & $A 42,88 b$ & $\mathrm{AB} 40,81 \mathrm{~b}$ & $38,71 b$ \\
\hline 50 & C 32,13 & BC 38,25 & A 44,50 & $\mathrm{~A} 46,25 \mathrm{ab}$ & $A B 45,31 b$ & $41,29 b$ \\
\hline 70 & C 34,44 & $\mathrm{BC} 39,88$ & A 43,38 & A $53,13 a$ & A 53,56a & $44,68 \mathrm{a}$ \\
\hline Médias & C 31,56 & B 37,75 & A 43,69 & A 46,47 & A 45,80 & \\
\hline
\end{tabular}

Em cada linha, médias seguidas da mesma letra maiúscula, e em cada coluna, médias precedidas da mesma letra minúscula não diferem significativamente entre si, ao nivel de $5 \%$, pelo teste de Tukey.

de 90,120 e 150 dias mostraram alturas superiores estatisticamente ao periodo de 30 dias. Para o sombreamento de $50 \%$, os resultados de altura foram estatisticamente semelhantes aos obtidos com o sombreamento de $30 \%$.

Em relação ao sombreamento de $70 \%$, os dados da Tabela 1 mostram que não ocorreram diferenças estatisticas na altura das mudas entre os periodos 120 e 150 dias, sendo superiores aos períodos de 30,60 e 120 dias.

No período de 120 dias, não ocorreram diferenças significativas na altura das mudas para os sombreamentos de 50 e $70 \%$, entretanto o nivel de $70 \%$ mostrou-se estatisticamente superior aos níveis de $0 \%$ e $30 \%$. No que se refere ao período de 150 dias, verificou-se que não houve diferenças significativas na altura das mudas entre os sombreamentos de 0,30 e $50 \%$, sendo estatisticamente inferiores quando comparados ao nível de $70 \%$.

A Tabela 2 mostra as médias de diâmetro do colo das mudas de jacareúba obtidas de acordo com os periodos de avaliação e níveis de sombreamento testados. As mudas avaliadas com 150 dias apresentaram resultados significativamente superiores às avaliadas nos demais periodos. Observou-se que não ocorreram diferenças estatísticas no diâmetro do colo entre os níveis de 30,50 e $70 \%$, ao final do experimento, sendo que estes apresentaram resultados estatisticamente superiores em relação ao sombreamento de $0 \%$.

Em estudos realizados por BARBOSA (1985) com mudas de morototó (Schefflera morototoni) observou-se que o sombreamento aumentou o diâmetro do colo à medida que as mudas permaneciam por período mais prolongado. Entretanto, FERREIRA et al. (1981) observaram variações acentuadas no diâmetro do colo das mudas de Pinus insularis em função dos niveis de sombreamento. $\mathrm{O}$ diâmetro do colo foi maior quando as mudas não foram sombreadas e reduziu em conseqüência do sombreamento.

Verificou-se através da Tabela 2 que as mudas cultivadas em condições de $30 \%$ de sombreamento apresentaram resultados estatisticamente semelhantes entre os períodos de 90 e 150 dias e mostraram valores superiores em relação aos períodos de 30 e 120 dias. Sob sombreamento de $50 \%$, não ocorreram diferenças significativas no diâmetro de colo das mudas entre os 
Tabela 2. Médias de diâmetro(mm) do colo das mudas de jacareúba obtidas de acordo com os períodos de avaliação e níveis de sombreamento testados.

\begin{tabular}{|c|c|c|c|c|c|c|}
\hline \multirow{2}{*}{ Somb. $(\%)$} & \multicolumn{6}{|c|}{ PERÍODOS (dias) } \\
\hline & 30 & 60 & 90 & 120 & 150 & Médias \\
\hline 0 & 0,25 & 0,26 & $0,28 \mathrm{~b}$ & $0,27 b$ & $0,28 b$ & $0,27 b$ \\
\hline 30 & C 0,25 & $\mathrm{BC} 0,29$ & $A B 0,31 a$ & C $0,27 b$ & A $0,34 a$ & $0,29 a$ \\
\hline 50 & C 0,25 & BC 0,29 & A $0,34 a$ & $\mathrm{~B} 0,30 \mathrm{a}$ & $A B 0,32 a$ & $0,30 \mathrm{a}$ \\
\hline 70 & C 0,27 & BC 0,28 & $c 0,28 \mathrm{~b}$ & $\mathrm{AB} 0,33 \mathrm{a}$ & $A 0,36 a$ & $0,31 a$ \\
\hline Médias & C 0,26 & B 0,28 & B 0,30 & B 0,29 & $A 0,32$ & \\
\hline
\end{tabular}

Em cada linha, médias seguidas da mesma letra maiúscula, e em cada coluna, médias precedidas da mesma letra minúscula não diferem significativamente entre si, ao nivel de $5 \%$, pelo teste de Tukey.

períodos de 90 e 150 dias e esses resultados foram superiores ao obtido com 30 dias. Para o sombreamento de $70 \%$, os períodos de 120 e 150 dias mostraram valores de diâmetro do colo estatisticamente semelhantes e superiores ao obtido com 30 dias.

No período de 90 dias, conforme mostra a Tabela 2, não ocorreram diferenças significativas no diâmetro do colo das mudas cultivadas sob sombreamento de 30 e $50 \%$, entretanto foram estatisticamente superiores aos niveis de 0 e $70 \%$. No que se refere ao período de 120 dias, verificou-se que não ocorreram diferenças significativas no diâmetro do colo das mudas entre os sombreamentos de 50 e $70 \%$, sendo estatisticamente superiores quando comparados aos niveis de 0 e $30 \%$. As mudas avaliadas com 150 dias apresentaram valores de diâmetro do colo estatisticamente semelhantes nos sombreamentos de 30,50 e $70 \%$ e mostraram valores superiores em relação ao sombreamento de $0 \%$.

A Tabela 3 mostra as médias de área foliar das mudas de jacareúba obtidas de acordo com os períodos de avaliação e niveis de sombreamento testados. Observou-se que a área foliar das mudas avaliadas com 150 dias foi estatisticamente superior as obtidas nos demais periodos. Verificou-se que não foram encontradas diferenças significativas na área foliar entre os períodos de 60,90 e 120 dias; as mudas avaliadas com 90 e 120 foram estatisticamente superiores as avaliadas com 30 dias.

Tabela 3. Médias de área foliar $\left(\mathrm{dm}^{2}\right)$ das mudas de jacareúba obtidas de acordo com os periodos de avaliação e níveis de sombreamento testados.

\begin{tabular}{crrrrrr}
\hline \multirow{2}{*}{ Somb. (\%) } & \multicolumn{7}{c}{ PERÍODOS (dias) } \\
\cline { 2 - 7 } & 30 & 60 & 90 & 120 & 150 & Médias \\
\hline 0 & 52 & 79 & 78 & 69 & 77 & $72 \mathrm{c}$ \\
30 & 56 & 80 & 107 & 93 & 146 & $97 \mathrm{~b}$ \\
50 & 64 & 87 & 105 & 122 & 170 & $110 \mathrm{~b}$ \\
70 & 86 & 127 & 139 & 170 & 198 & $144 \mathrm{a}$ \\
\hline Médias & C 65 & BC 94 & B 108 & B 114 & A 148 & \\
\hline
\end{tabular}

As médias seguidas na linha pela mesma letra e na coluna pela mesma letra não diferem entre si, ao nivel de $5 \%$ de probabilidade, pelo teste de Tukey. 
Os dados da Tabela 3 mostram que sob sombreamento de $70 \%$ as mudas apresentaram área foliar superior aos demais sombreamentos testados. As médias de área foliar das mudas cultivadas sob sombreamento de 30 e $50 \%$ não diferiram estatisticamente entre si e foram superiores quando comparadas com $0 \%$. Observou-se, portanto, que o maior sombreamento aumentou a área foliar das mudas da espécie em estudo. BARBOSA (1985), em mudas de morototó (Schefflera morototoni) observou maior valor de área foliar quando cultivadas em ambientes mais sombreados. PEDROSO \& VARELA (1995), também, verificaram que a área foliar nas mudas de sumaúma (Ceiba pentandra) sob $70 \%$ de sombreamento foi estatisticamente superior quando comparada com a obtida no nível de $30 \%$. O aumento da área foliar com sombreamento é uma das formas da planta aumentar rapidamente a superficie fotossintetizante e assegurar um aproveitamento maior das baixas intensidades luminosas. Entretanto, nas mudas de Eucalyptus grandis, GOMES et al. (1978) constataram aumento significativo nos valores de área foliar na ausência de sombreamento.

As médias de taxas de crescimento relativo foliar (TCRF) e da razão de área foliar (RAF) das mudas de jacareúba (Calophyllum angulare) obtidas em diferentes períodos de permanência no viveiro encontram-se na Tabela 4.

Observou-se que a taxa de crescimento relativo foliar (TCRF) das mudas com 30 dias de permanência no viveiro foi estatisticamente superior em
Tabela 4. Médias da taxa de crescimento relativo foliar (TCFR) e da razão de área foliar (RAF) das mudas de jacareúba(Calophyllum angulare) obtidas em diferentes períodos de permanência no viveiro.

\begin{tabular}{cll}
\hline $\begin{array}{c}\text { Periodos } \\
\text { (dias) }\end{array}$ & $\begin{array}{c}\text { TCFR } \\
\mathrm{g} / \mathrm{g} / 30 \text { dias }\end{array}$ & $\begin{array}{c}\text { RAF } \\
\mathrm{cm}^{2} / \mathrm{g}\end{array}$ \\
\hline 30 & $0.023 \mathrm{a}$ & $88.637 \mathrm{a}$ \\
60 & $0.012 \mathrm{ab}$ & $83.116 \mathrm{ab}$ \\
90 & $0.008 \mathrm{ab}$ & $75.515 \mathrm{bc}$ \\
120 & $0.002 \mathrm{~b}$ & $71.144 \mathrm{c}$ \\
150 & $0.013 \mathrm{ab}$ & $70.274 \mathrm{c}$ \\
\hline F & $2.02^{*}$ & $11.98^{* *}$ \\
DMS & 0.022 & 8.988 \\
\hline
\end{tabular}

* Significativo para o teste $\mathrm{F}$ ao nivel de $5 \%$ de probabilidade.

** Significativo para o teste $\mathrm{F}$ ao nivel de $1 \%$ de probabilidade.

As médias seguidas pela mesma letra não diferem estatisticamente, ao nivel de $5 \%$ de probabilidade, pelo teste de Tukey.

relação ao valor observado aos 120 dias e que não ocorreram diferenças significativas entre os períodos de 60 , 90,120 e 150 dias.

Com relação a razão de área foliar (RAF) verificou-se que as mudas com 30 dias apresentaram um valor estatisticamente superior ao observado nas mudas com 90, 120 e 150 dias. Observouse ainda que não foram encontradas diferenças significativas na razão de área foliar entre os períodos de 30 e 60 dias e também aos 90,120 e 150 dias de permanência no viveiro. Nos estudos realizados sobre o crescimento de mudas de pupunheira (Bactris gasipaes), GARCIA \& FONSECA (1991) observaram que a taxa de crescimento relativo foliar (TCFR) e a razão de área foliar (RAF) foram decrescentes em função da idade das mudas.

No presente estudo, exceto aos 150 dias, houve uma tendência de ocorrer um decréscimo nos valores de 
taxa de crescimento relativo foliar (TCRF) com o periodo de permanência no viveiro. Os valores de razão de área foliar (RAF) também apresentaram tendência ao decréscimo em decorrência do período de permanência no viveiro. Estes dados permitem observar que, com o crescimento da planta, ocorre $u$ um decréscimo na taxa de crescimento relativo foliar (TCRF) e na razão de área foliar (RAF), que pode ser explicado pelo aumento na interferência de folhas superiores sobre as folhas inferiores, ou seja, pelo auto-sombreamento.

As médias de taxa de crescimento relativo foliar (TCRF) e a razão de área foliar (RAF) das mudas de jacareúba (Calophyllum angulare) obtidas em função dos níveis de sombreamento são apresentadas na Tabela 5 .

Observou-se que não ocorreram diferenças significativas nas taxas de crescimento relativo foliar (TCRF) entre os niveis de sombreamento de 0 ,

Tabela 5. Médias da taxa de crescimento relativo foliar (TCFR) e da razão de área foliar (RAF) das mudas de jacareúba (Calophyllum angulare) obtidas em função dos níveis de sombreamento.

\begin{tabular}{ccc}
\hline $\begin{array}{c}\text { Niveis de } \\
\text { sombreamento }\end{array}$ & $\begin{array}{c}\text { TCFR } \\
\mathrm{g} / \mathrm{g} / 30 \mathrm{dias}\end{array}$ & $\begin{array}{c}\text { RAF } \\
\mathrm{cm}^{2} / \mathrm{g}\end{array}$ \\
\hline $0 \%$ & 0.013 & $70.418 \mathrm{~b}$ \\
$30 \%$ & 0.010 & $73.949 \mathrm{~b}$ \\
$50 \%$ & 0.011 & $76.321 \mathrm{a}$ \\
$70 \%$ & 0.010 & $90.260 \mathrm{a}$ \\
F s & 0.09 n.s. & $17.98^{* *}$ \\
\hline F sP & 0.91 n.s. & 1.62 n.s. \\
DMS & - & 7.562 \\
\hline
\end{tabular}

n.s. - Não significativo para o teste $\mathrm{F}$ para $5 \%$ de probabilidade.

** - Significativo para o teste $\mathrm{F}$ para $1 \%$ de probabilidade.

As médias seguidas pela mesma letra não diferem estatisticamente, ao nível de $5 \%$ de probabilidade, pelo teste de Tukey.
30,50 e $70 \%$. As médias da razão de área foliar (RAF) nos niveis de sombreamento de 0,30 e $50 \%$ foram estatisticamente equivalentes entre si. $\mathrm{O}$ nivel de $70 \%$ de sombreamento proporcionou um valor estatisticamente superior em relação aos demais níveis de sombreamento, PEDROSO \& VARELA (1995), observaram que a razão de área foliar (RAF) em mudas de sumaúma (Ceiba pentandra) sob 50 e $70 \%$ de sombreamento não mostraram diferenças estatísticas entre si e foram superiores aos valores observados nas produzidas sob $30 \%$ de sombreamento. Os resultados obtidos em função da razão de área foliar parecem indicar que a jacareúba (Calophyllum angulare) é favorecida em ambientes sombreados.

A Figura 1 mostra a variação da taxa de crescimento relativo da parte aérea (TCRPA) pelas mudas de jacareúba cultivadas sob $0,30,50$ e $70 \%$ de sombreamento. Sob $70 \%$ de sombreamento houve um decréscimo da taxa de crescimento relativo da parte aérea das mudas entre 30 e 60 dias de avaliação, havendo uma tendência de estabilização a partir de 60 dias. Levando em consideração esse parâmetro, as mudas cultivadas sob $70 \%$ de sombreamento apresentaram valores que indicam uma melhor adaptação a essa condição.

As mudas cultivadas sob $0 \%$ de sombreamento mostraram um decréscimo contínuo no crescimento relativo da parte aérea entre os períodos de 30 e 120 dias; neste último período alcançou um valor negativo e posteriormente houve um acréscimo elevado entre 120 e 150 dias.

Sob sombreamento de $50 \%$, a taxa 


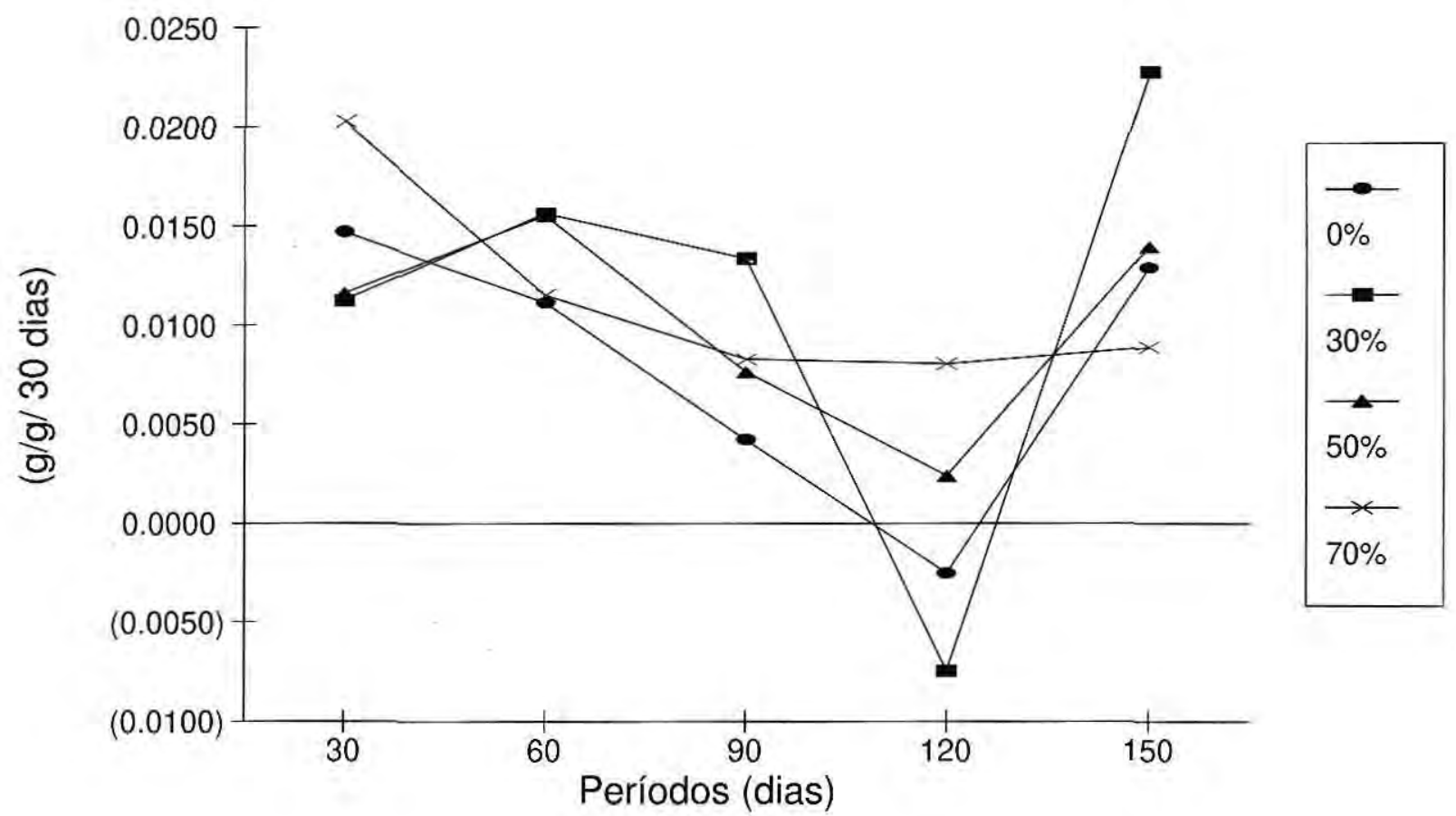

בิ

Figura 1. Variação da taxa de crescimento relativo da parte aérea (TCRPA) pelas mudas de jacareúba (Calophyllum angulare), cultivadas sob $0,30,50$ e $70 \%$ de sombreamento. 
de crescimento relativo da parte aérea apresentou um ligeiro acréscimo entre 30 e 60 dias coincidindo com a taxa de crescimento relativo da parte aérea observada no sombreamento de $30 \%$. A partir deste periodo houve um decréscimo gradativo até 120 dias de permanência das mudas no viveiro, mostrando nesse período o menor valor observado. No período de 120 a 150 dias de permanência das mudas no viveiro, houve um acréscimo na taxa de crescimento relativo da parte aérea.

Observou-se que sob $30 \%$ de sombreamento, as variações na taxa de crescimento relativo da parte aérea foram mais acentuadas que aquelas observadas nos outros níveis de sombreamento testados. Observou-se ainda uma queda brusca entre 90 e 120 dias de avaliação, onde constatou-se um crescimento negativo e inferior aos observados em outros níveis de sombreamento, apresentando entre 120 e 150 dias seu maior incremento.

No período de 120 dias de permanência das mudas no viveiro, verificou-se um decréscimo na taxa de crescimento relativo da parte aérea nos níveis de 0,30 e $50 \%$. Esses niveis de sombreamento podem ter ocasionado uma redução no teor de clorofila, e, conseqüentemente, um menor acúmulo de fotoassimilados.

A Figura 2 mostra a variação da taxa de crescimento relativo das raízes (TCRRA) pelas mudas de jacareúba, (Calophyllum angulare), cultivadas sob $0,30,50$ e $70 \%$ de sombreamento. Sob $70 \%$ de sombreamento houve uma maior oscilação na taxa de crescimento relativo das raizes, , mostrando um decréscimo acentuado entre 30 e 60 dias, um acréscimo linear entre 60 e 120 dias e posteriormente um decréscimo entre 120 a 150 dias de permanência no viveiro.

Sob $0 \%$ de sombreamento houve um decréscimo contínuo na taxa de crescimento relativo das raizes entre $30 \mathrm{e}$ 90 dias; neste último período de avaliação coincidiu com o valor observado no sombreamento de $70 \%$ e a partir de 90 dias ocorreu uma tendência à estabilidade.

Nas mudas cultivadas sob $30 \%$ de sombreamento, ocorreu uma tendência de estabilização na taxa de crescimento relativo das raizes entre 30 e 90 dias, entretanto entre os periodos de 90 a 120 dias houve um decréscimo acentuado nesta taxa, atingindo um valor minimo neste periodo. A partir de 120 dias, houve um acréscimo na taxa de crescimento relativo das raizes até 150 dias.

Sob $50 \%$ de sombreamento, ocorreu um leve decréscimo na taxa de crescimento relativo das raizes entre 30 a 60 dias de permanência das mudas no viveiro seguido de uma queda acentuada entre 60 e 90 dias e tendendo a uma estabilização a partir de 90 dias. Nas condições experimentais utilizadas, os niveis de sombreamento mais favoráveis foram 0 e $50 \%$.

Observou-se aos 120 dias que a taxa de crescimento relativo da parte aérea no nivel de $70 \%$ de sombreamento foi maior em relação aos outros niveis de sombreamento. Verificou-se também que neste período e sombreamento, a taxa de crescimento relativo das raizes foi maior, o que se pode deduzir que houve uma translocação de fotoassimilados da parte 


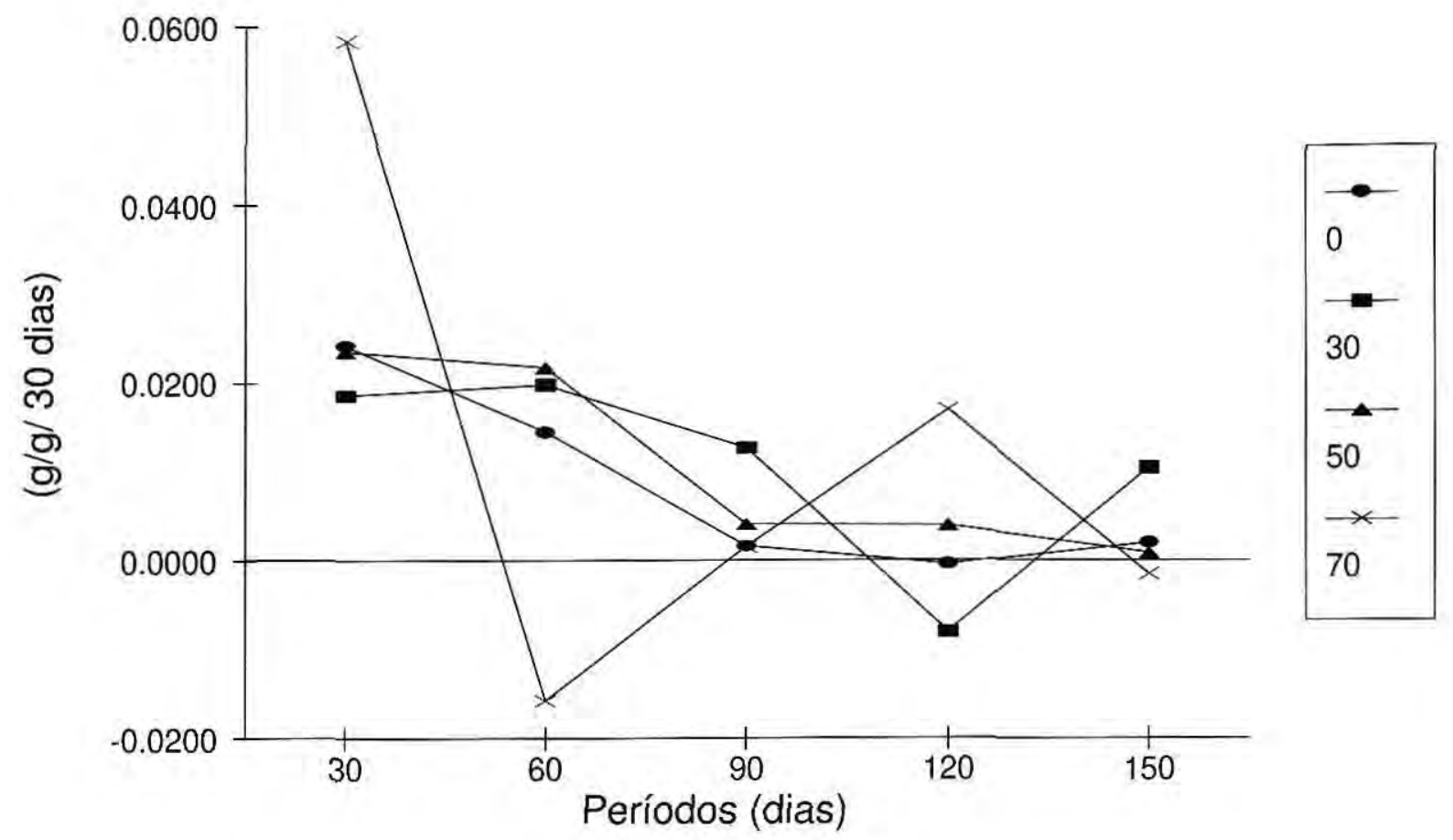







aérea para a raiz.

A Figura 3 mostra a variação da taxa de crescimento relativo total (TCRT) pelas mudas de jacareúba cultivadas sob 0,30 , 50 e $70 \%$ de sombreamento. Sob este último nível, houve um ligeiro decréscimo da taxa de crescimento relativo total entre 30 a 90 dias de permanência das mudas no viveiro, um acréscimo entre 90 e 120 dias e em seguida um ligeiro decréscimo entre 120 a 150 dias.

As mudas cultivadas sob $0 \%$ de sombreamento apresentaram um decréscimo contínuo da taxa de crescimento relativo total entre 30 e 120 dias, apresentando um valor negativo neste último período e, em seguida, houve um acréscimo acentuado entre 120 e 150 dias de permanência das mudas no viveiro.

Sob sombreamento de $50 \%$, a taxa de crescimento relativo total (TCRT), apresentou um ligeiro decréscimo entre os períodos de 30 e 120 dias e houve um ligeiro acréscimo de 120 a 150 dias; neste último período coincidiu com a taxa de crescimento relativo total (TCRT) observado no sombreamento de $0 \%$.

Sob $30 \%$ de sombreamento, observou-se que ocorreu uma variação na taxa de crescimento relativo total mais acentuada quando comparada com os demais níveis de sombreamento testados. Houve uma queda brusca entre 90 e 120 dias de avaliação, constatando-se um crescimento negativo neste periodo e inferior ao observado em outros niveis de sombreamento. A partir de 120 dias, as mudas cultivadas sob $30 \%$ apresentaram um incremento acentuado nos valores de taxa de crescimento relativo total.
Analisando-se as Figuras1, 2 e 3 observou-se que entre os períodos de $30 \mathrm{a}$ 60 dias, o crescimento foi afetado pela aclimatação das mudas cultivadas no nível de sombreamento de $70 \%$. Nesse intervalo, as taxas de crescimento relativo da parte aérea (TCRPA), crescimento relativo das raizes (TCRRA) e crescimento relativo total (TCRT) cairam de 0.0203 para 0.0115 , 0.0584 para -0.0157 e 0.0229 para 0.0119 $\mathrm{g} / \mathrm{g} / 30$ dias, respectivamente. A retomada do aumento da taxa de crescimento relativo das raízes (TCRRA) ocorreu a partir de 60 dias de avaliação. Notase, portanto, que o efeito da aclimatação sobre as mudas cultivadas sob $70 \%$ de sombreamento produziu uma diminuição temporária no crescimento das raizes, com subseqüente recuperação após 60 dias.

\section{CONCLUSÕES}

Os maiores valores de altura e área foliar foram alcançados quando as mudas foram cultivadas sob $70 \%$.

Os melhores resultados de diâmetro do colo e área foliar foram obtidos quando as mudas foram avaliadas com 150 dias. Os sombreamentos de 30,50 e $70 \%$ proporcionaram um melhor desenvolvimento de diâmetro do colo das mudas.

A taxa de crescimento relativo foliar (TCRF) e a razão de área foliar (RAF) das mudas com 30 dias de permanência no viveiro foram estatisticamente superiores em relação aos valores observados aos 120 dias.

Ocorreu uma tendência de decréscimo nos valores de taxa de crescimento relativo foliar (TCRF) e de razão de área foliar (RAF) em 
decorrência do período de permanência das mudas no viveiro;

Os niveis de sombreamento testados não influenciaram na taxa de crescimento relativo foliar (TCRF);

As mudas cultivadas sob $70 \%$ a. sombreamento apresentaram um valor de razão de área foliar (RAF) superior aos demais niveis de sombreamento. Estes resultados indicam que a jacareúba (Calophyllum angulare) é favorecida em ambientes sombreados;

As mudas cultivadas sob $70 \%$ apresentaram valores de taxa de crescimento relativo da parte aérea que indicam uma melhor adaptação a essa condição. Com relação a taxa de crescimento relativo das raizes, os niveis de sombreamento que apresentaram maior estabilidade foram 0 e $50 \%$.

Observou-se que o efeito da aclimataçâo sobre as mudas cultivadas sob $70 \%$, provocou uma diminuição temporária nas taxas de crescimento relativo da parte aérea (TCRPA) e crescimento relativo total (TCRT), entre os períodos de 30 a 60 dias.

\section{Bibliografia citada}

ALENCAR, J. da C; ALMEIDA, R.A. de S: FERNANDES, N.P. 1979. Fenologia de espécies florestais em floresta tropical úmida de terra firme na Amazônia Central. Acta Amazonica, 9(1):163-198.

BARBOSA, A. P. 1985. Ecofisiologia do crescimento inicial de mudas de morototo (Schefflera morototoni. Aubl. Frondin-Araliaceae) cultivadas sob quatro niveis de radiação solar e très niveis de espaçamento. Dissertação de Mestrado. Manaus, INPA/FUA,. 95p.

BLACKMAN, G. E.; WILSON, G. L. 1956. Physiological and ecological studies in the analysis of the plant environment, VII analysis of the differential effects of light intensity on the net assimilation rate, leaf-area ratio and relative growth rate of diferent species. Annals of Botany, Oxford, 43(8): 557-61.

BLACKMAN, G. E. 1968. The aplication of the concepts of growth analysis to the assessment of productivity. In: ECKARDT, F. E. (ed.) Function of terrestrial ecossystems at the primary production level. Copenhagem. Procedings. Paris, UNESCO, p 243-59.

CLARKE, G.L. 1971. Elementos de ecologia. Barcelona, Omega, 637 p.

FAIRBAIRN, W. A.; NEUSTEIN, S. A. 1970. Study of response of certain coniferous species to light intensity, Forestry; 43 (1): $57-71$.

FERREIRA, M. G. M.; CANNDIDO, J. F.; CANO, M. A.; CONDE, A. R. 1977. Efeito do sombreamento na produção de mudas de quatro especies florestais nativas. Rev. Anore, Viçosa, 1 (2): 121-34.

FERREIRA, M. G. M.; CÂNDIDO, J. E.: SILVA, P. A.; COLODETTE, J. L. 1981. Efeito do sombreamento e da densidade de sementes sobre o desenvolvimento de mudas de "Pinus insularis" Endlichere seu crescimento inicial no campo. Res. Arvore, 2 (1): 53-61.

GARCIA, T, B; FONSECA, C. E. L. da. 1991. Crescimento de mudas de pupunheira em condiçòes de viveiro coberto com palha, Pesq. Agrop. Bras., Brasilia, 26 (9): 1447-1451.

GOMES, J. M.; FERREIRA, M. G. M; BRANDT, R. M.; NETO, F. P. 1978. Influência do sombreamento no desenvolvimento de Eucalyptus grandis W. Hill ex Maiden. Revista Anore, 2(1):68-75

GRIME, J. P. 1965. Shade tolerance in flowering plants. Nature, London, 218(5006): 61-3.

LEVITT, J, 1972. Responses of plants to environmental stress. New York, Academic Press, $607 \mathrm{p}$.

PEDROSO, S. G.; VARELA, V. P. 1995. Efeito do sombreamento no crescimento de mudas 
de sumaúma (Ceiba pentandra(L.) Gaertn) Rev. Bras. de Sementes, 17 (1): 47-51.

PINTO, A. M,; VARELA, V. P.; BATALHA, L. F. P. 1993. Influência do sombreamento no desenvolvimento de mudas de Louro pirarucu (Licaria canella (Meissn.) Kosterm). Acta Amazonica, 23 (4): 397-404.

PHILLIPS, I. D. J. 1969. Apical dominance. In: The physiology of plant growth on development (Ed. Malcolm B. Wilkins). Mcgraw- Hill. London.

PHILLIPS, I. D. J. 1975. Apical dominance. Ann. Rev. Plant Physiology, 26: 341-367.

POGGIANI, F.; BRUNT, S.; BARBOSA, E. S. Q. 1992. Efeito do sombreamento sobre o crescimento das mudas de três espécies florestais. In: Anais de $2^{\circ}$ Congresso Nacional sobre Essências Nativas, 4 ( ${ }^{\circ}$ único): 564-569.
RADFORD, P. J. 1967. Growth analysis formulae; their use and abuse. Crop. Sci, 7: 171-175.

RIBEIRO, M. N. G. 1976. Aspectos climatológicos de Manaus. Acta Amazonica, 6 (2): 229-233,

STURION, J. A.; IEDE, E. T. 1982. Influência da profundidade da semeadura, cobertura do canteiro e sombreamento na formação de mudas de Ocotea porosa (Nees) Liberato Barroso (Imbuia). In: IV Congresso Florestal Brasileiro, Belo Horizonte, 28: 513-6.

VARELA, V. P.; SANTOS, J. dos. 1992. Influência do sombreamento na produção de mudas de Angelim pedra (Dinizia excelsa Ducke). Acta Amazonica, 22 (3): 407-411. 